\title{
COMO O RISO ERA CONCEBIDO NO SÉCULO XVI
}

\author{
Vera Cecília MACHLINE ${ }^{1}$
}

- RESUM 0: Este artigo considera que o riso desperta, pelo menos no mundo ocidental, um misto de cautela no trato social e prestígio de ordem terapêutica desde os tempos bíblicos. No século XVI, em particular, afora buscar-se conhecer a natureza do risível, amiúde recomendava-se rir com moderação por motivos não só de urbanidade, como também de fisiologia.

- PALAVRAS-CHAVE: Riso; alegria; paixões; fisiologia antiga; galenismo.

A tualmente, o riso é definido como uma expressão psicomotora de alegria, prazer ou sentimentos afins, às vezes conjugando ag ressividade ou angústia, que se manifesta mediante a contração de músculos faciais, peitorais e abdominais, bem como expirações curtas mais ou menos ruidosas e um ligeiro aumento dos batimentos cardíacos. Já gargalhadas prolongadas e intensas têm efeitos distintos. Podem provocar lágrimas, dores, acessos de tosse ou soluço e, ocasionalmente, até um infarto.

Segundo antropólogos e etologistas, o riso pode ter surgido do comportamento ainda hoje observado entre símios antropóides, de arreganhar os dentes e emitir gritos intimidativos, para ameaçar um estranho ou um conhecido indesejável. Possivelmente oriundo dessa rudimentar forma de advertência, o riso veio a constituir uma resposta estereotipada

1 Programa de Estudos Pós-Graduados em História da Ciência - Pontifícia Universidade Católica de São Paulo. 
a certos estímulos. Os mais simples incluem cócegas e excitações anômalas. Dentre os dotados de um elevado grau de complexidade, destacam-se os estímulos humorísticos contendo elementos de incongruência cognitiva.

À primeira vista inócua, a faculdade humana de rir vem despertando, pelo menos no mundo ocidental, um misto de cautela no trato intersocial e prestígio de ordem terapêutica desde os tempos clássicos. Aliás, segundo sugerido por textos do A ntigo Testamento, atitude semeIhante também parecia prevalecer nos ensinamentos bíblicos. Por exemplo, de um lado, o Eclesiastes $(7,3)$ recomenda que "Mais vale o desgosto do que o riso, / pois pode-se ter a face triste e o coração alegre". De outro, os Provérbios $(17,22)$ sustentam: "Coração alegre, corpo contente; / espírito abatido, ossos secos".

Com base no princípio do meio-termo, A ristóteles (284-322 a.C.) recorre ao riso no capítulo 8, Livro 4, de sua Ética a Nicômaco para sugerir que a recreação após as atividades costumeiras deveria igualmente pautar-se pelo bom gosto. Nas palavras do filósofo, sua escolha foi motivada pelo fato de que não é nada "difícil descobrir o lado ridículo das coisas, e a maioria das pessoas deleita-se mais do que devem com gracejos e caçoadas". Mas dado ser próprio "de um homem de tato dizer e escutar aquilo que fica bem a uma pessoa digna e bem-educada", por via de regra, seus chistes "diferem dos de um homem vulgar, assim como os de uma pessoa instruída diferem dos de um ignorante" (Aristóteles, 1987, p.75-76).

A praticidade do assunto foi aprofundada sem demora pela retórica romana clássica. Cícero (106-43 a. C.), por exemplo, no Livro 2 de seu De oratore afirma que "convém a um orador provocar o riso, e isso por vários motivos". Dentre outros, menciona que um dito divertido naturalmente angaria benevolência para seu autor; aniquila, desconcerta ou faz pouco de um oponente; revela que o orador é um homem erudito e urbano; alivia o tédio e abranda a austeridade, além de freqüentemente desvanecer insinuações desagradáveis, dificilmente dissipadas por argumentos (Cícero, 1988, p.372-5). A pesar de tais vantagens, as coisas risíveis exigiriam do orador a mais cuidadosa consideração. Para demonstrar isso, pelo restante do Livro 2 Cícero esmiuça chistes retóricos exemplares. J ulgando que ainda cabiam reparos adicionais, Quintiliano (c. 25-c. 96 d. C.) retoma a questão no capítulo 3, Livro 4, de sua Institutio oratoria.

$\mathrm{Na}$ esteira do movimento humanista inaugurado por Francesco Petrarca (1304-1373), preocupações alheias à Igreja deflagraram uma 
veemente intolerância com gargalhadas e zombarias passíveis de perturbar o convívio social. Um fator crucial parece ter sido o "processo civilizador" descrito por Elias (1994). Aliado à retomada do estoicismo via pensadores latinos, esse processo foi responsável pela promoção do autocontrole do corpo e das funções orgânicas mediante a razão. Em outras palavras, trata-se da difusão das normas de boas maneiras que, do quatrocentos em diante, paulatinamente vieram a se estender das cortes palacianas aos lares burgueses.

Um veículo de propagação eficaz foi a extensa série de manuais sobre a arte da conversação. A pesar de vigorarem pelo século XIX adentro, o mais famoso continua sendo 0 cortesão, de autoria do conde Baldassare Castiglione (1478-1529). No seu entender,

tudo aquilo que provoca o riso alegra o espírito e dá prazer, não deixando que naquele instante a gente se lembre das doenças irritantes de que nossa vida está cheia. Por isso ... o riso é apreciadíssimo e é muito louvável quem o promove oportunamente e com boas maneiras.

\section{Outrossim, Castiglione reconhece sua incapacidade de dizer}

o que será esse riso, onde estará e de que modo às vezes ocupa as veias ... e os flancos, parecendo que nos queira fazer explodir, tanto que por mais força que façamos não é possível contê-lo. (1997, p.134-4)

Como Cícero, Castiglione deixa essa discussão "para Demócrito que, mesmo que prometesse, não seria capaz de explicá-lo". Aos menos avisados cumpre esclarecer que, longe de ser o pré-socrático de Abdera responsável por elaborar o atomismo de seu mestre Leucipo (florescido em 430 a. C.), trata-se do lendário filósofo ridente, imortalizado por Cícero, Horácio (65 a. C.-8 d. c.) e Sêneca, o J ovem (c. 4 a. C.-65 d. C.), assim como mediante uma coleção de 14 diatribes epistolares pseudohipocráticas escritas entre os séculos I a. C. e II d. C., hoje conhecidas como Cartas de Demócrito.

0 desinteresse de Castiglione por desvendar a natureza do riso constituiu exceção na intelectualidade quinhentista. Esta, em sua maioria, dispôs-se a desvendar o "risível", ou seja, o móvel que leva o ser humano a rir, fundamentada em princípios fisiológicos distintos dos atuais, a começar pela ausência da doutrina do reflexo, que veio a se estabelecer na segunda metade do século XIX, para explicar o movimento muscular animal. Antes disso, o riso era amiúde tido como uma dentre cerca de trinta "paixões" da alma ou da mente. Hoje conhecidas como emoções, 
eram consideradas movimentos sensórios responsáveis por alterações passivas no corpo, provocadas pela imaginação de um bem ou um mal.

Em outras palavras, o impacto das paixões sobre o organismo era antigamente visto sobretudo em termos somáticos. De acordo com a fisiologia aristotélica, por sediar as funções vitais e mentais, o coração respondia incontinênti a uma emoção. Dependendo da natureza aquecedora ou arrefecedora desta, ele se expandia ou se contraía. Por exemplo, a alegria e o prazer dilatavam o coração e aqueciam o organismo, enquanto a tristeza e o medo contraíam esse órgão e promoviam o frio a tomar conta do corpo. Já as paixões imoderadas, além de constituírem uma infração do meio-termo, se atingissem proporções paroxísmicas, poderiam provocar uma comoção cardíaca fulminante.

0 coração continuou sendo o centro da vida, a despeito da visão platônica de Galeno de Pérgamo (129-c. 199), que distribuiu entre o fígado, o coração e a mente as faculdades desiderativa, espiritualizada e racional da alma. M esmo conforme o galenismo, portanto, exceto quando a razão intervinha, o coração permanecia subserviente às paixões, cujos efeitos sobre o organismo incluíam alterações no ritmo cardíaco ou na mistura qualitativa dos humores, às vezes salutares, e outras vezes danosas.

Reconhecida desde os tempos bíblicos, a influência das emoções sobre a saúde foi formalmente sistematizada por um compêndio médico de autoria anônima vindo à luz no início do século XII. Intitulado Isagoge J ohannitti, este integrou as traduções latinas que vieram a compor 0 "novo" galenismo ensinado nas universidades logo mais estabelecidas no continente europeu. Desde então, juntamente com ar ambiente, comida e bebida, sono e vigília, atividade e repouso, evacuação e repleção, as paixões passaram a compreender um dos seis conjuntos de fatores "não-naturais" que, apesar de exógenos, eram capazes de alterar a constituição dos humores corporais e, daí, o delicado equilíbrio entre esses. Como se sabe, segundo os preceitos da medicina humoral, tais variações podiam tanto promover quanto prejudicar a disposição do organismo.

Dado seu valor terapêutico, os "seis não-naturais" subsistiram na forma de preceitos "higiênicos" até fins do século XIX. No baixo medievo, de pronto fizeram-se presentes nos consilia e regimina sanitatis então prescritos. Como seria de se esperar, a alegria era uma constante nesses receituários. A propósito, bem conhecida pelos historiadores da medicina é a recomendação no Regimen Sanitatis Salernitanum (Escola de Salerno, 1970) de diariamente recorrer-se a um alegórico “Doutor da Alegria" para se garantir uma boa saúde. Na versão elisabetana realizada por Sir J ohn Harington (1561-1612), este regime assevera: 
Por essas linhas a Escola de Salerno deseja

Toda a saúde ao Rei dos Ingleses e aconselha.

A mente mantenha livre de cuidados, e da ira o coração,

Não beba muito vinho, ceie pouco, levante cedo,

Depois de comer, ficar sentado causa danos; ...

E use ainda três médicos, primeiro o Doutor Descanso,

Depois o Doutor Alegria, e o Doutor Dieta. (Rosen, 1994, p.70)

A elevada reputação da alegria explica costumes de outrora, como manter conversas amenas e ler ou ouvir histórias engraçadas. A alegria era bem-vista, contudo, desde que moderada. Em grau demasiado, poderia ser fatal, segundo sugeriam antigos casos de óbito registrados pelo enciclopedista latino Plínio, o Velho (23-79 d.C.). Ocasionadas por uma boa nova inesperada, essas ocorrências foram levadas em consideração no século XVI, dado rir parecer afim de rompantes de alegria intensa. Por sinal, assim pensava boa parte da intelectualidade quinhentista, como o humanista de berço hispânico J uan Luis Vives (1990) (c. 1492-1560) e 0 professor de medicina da Universidade de Turim F rançois Valeriole (15041580). Já outra parte ponderou que o riso também pressupunha pesar.

Uma fonte que contribuiu para esta visão foi a Poética aristotélica, depois de permanecer esquecida por séculos no Ocidente. Com sua revivescência, que mesmo na península itálica só tomou fôlego em meados do século XVI, vários tradutores foram instados a complementarem as reticentes informações sobre 0 risível contidas no capítulo 5 desse hoje renomado tratado. Só para lembrar, lá consta que, em comparação com a tragédia, a comédia seria a "imitação de homens inferiores ... mas só quanto àquela parte do torpe que é o ridículo". Este, por sua vez, é definido como "certo defeito, torpeza anódina e inocente; que bem o demonstra, por exemplo, a máscara cômica, que sendo feia e disforme, não tem [expressão de] dor" (Aristóteles, 1987, p.205).

Com base nessas passagens, mas também influenciado pela interpretação ciceroniana a respeito, o bresciano Vincenzo Maggi (c. 15001564) concluiu que rir advinha da justaposição de duas paixões contrárias. De acordo com sua glosa De ridiculis, o riso seria provocado por um duplo movimento de dilatação e contração, derivado de um misto de prazerosa admiração e dolorosa torpitude.

Mesmo não dispondo de uma cópia da Poética, o médico da Universidade de Montpellier Laurent Joubert (1529-1582) (1973) chegou a uma proposta semelhante à de Maggi. Diferentemente deste, porém, J oubert teria se apoiado apenas nas poucas conjecturas sobre o risível trazidas no já mencionado capítulo 2 do De oratore de Cícero (1988), a saber: 
o campo ou província ... do risível ... restringe-se ao que pode ser como impróprio ou feio; porque os principais, se não os únicos, motivos de riso são as afirmações que comentam ou apontam algo impróprio de maneira nada imprópria. (Cícero, 1988, p.372-3)

Supostamente valendo-se dessas poucas informações, J oubert (1973, p.16) sugere que o riso seria provocado por tudo que "fosse feio ou impróprio, mas desmerecesse pena ou compaixão". Daí, no seu entender, as coisas risíveis despertarem tristeza e alegria. A primeira provinha de sua feiúra ou impropriedade; e a segunda, da certeza de "não haver [nelas] nada que provocasse compaixão (além de uma falsa aparência)" (1973, p.83). Como a alegria sempre suplanta a tristeza, jamais ocorre qualquer dano, ou malefício sério, em assuntos risíveis. Isso posto, J oubert (1973, p.88) define ser 0 riso praticamente "o meio-termo entre a alegria e a tristeza, cada uma das quais, quando extremada, levava à morte". A pesar de a primeira exceder um pouco a segunda, essas duas paixões tendiam a se alternar quando se ria com sobriedade. Nesse caso, além de se evitar o perigo de uma dilatação ou contração temerária, era possível aumentar o calor natural e revigorar o organismo.

Os reparos de J oubert quanto ao riso não param por aí, mesmo porque, até notícia em contrário, afora uma versão preliminar, seu Traité du ris de 1579 parece ter sido a única publicação quinhentista inteiramente dedicada à faculdade humana de rir. Escrita em vernáculo e compreendendo três livros, a edição definitiva desta obra traz marcas do desígnio de Joubert de reivindicar a supremacia do médico com formação universitária sobre os assim chamados "empíricos" também atuando na medicina da época. Visando demonstrar a douta erudição de um médico num tópico tão candente e complexo quanto 0 riso, J oubert logra reunir um valioso acervo de idéias antigas e quinhentistas a respeito, como a existência de um riso genuíno e uma variante falsa. Em sintonia com as preocupações de seu tempo, igualmente advoga a conveniência de rir-se com moderação.

Nas suas palavras, quando o riso é "dissoluto ou de longa duração, a garganta se abre ao máximo, enquanto os lábios são puxados para trás em extremo" ... E, por isso, torna-se feio, impróprio e lascivo. De mais a mais, o riso imoderado cansa "os músculos, que ficam então incapacitados de fechar a boca e repô-la na posição certa, motivo pelo qual ela permanece indecentemente aberta" (J oubert, 1973, p.114-5). Outro efeito do riso exagerado seriam as rugas na face e em torno dos olhos. Segundo Joubert (p.116), para o bem de sua aparência, "as jovens são aconselhadas a evitar rir tolamente, e avisadas de que podem 
envelhecer mais cedo". Acrescente-se a semelhantes impropriedades 0 risco de depauperar o organismo rindo-se à toa, e fica claro por que J oubert adverte nas últimas páginas do Traité du ris que, dependendo do estado físico do indivíduo, até o riso moderado, assim como todo "não-natural", urge cautela.

Em conclusão, é provável que nunca se saiba ao certo o que nos leva a rir. Seja como for, na História da Ciência visualiza-se um ponto de vista privilegiado para se apreciar como o riso era antigamente visto e os meios de lidar-se com suas inconveniências e suas vantagens.

MACHLINE, V. C. The conception of laughter in the XVIth century. Trans/Form/ A ção (São Paulo), v.21-22, p.11-19, 1998-1999.

- ABSTRACT: In this article it is maintained that laughter has raised, at least in the Western World, since biblical times, both caution in social interaction and prestige as a therapeutical tool. In the XVIth century, in particular, the search for the nature of the laughable was promoted side by side with the recommendation that people should laugh in moderation out of urbanity and for physiological reasons.

- KEYWORDS: Laughter; joy; passions; ancient physiology; Galenism.

\section{Referências bibliográficas}

ARISTÓTELES. Ética a Nicômaco. São Paulo: Nova Cultural, 1987. v.2, p.5-196. . Poética. São Paulo: Nova Cultural, 1987, v.2, p.197-229.

BURKE, P. A arte da conversação no início da Europa moderna. In:

A arte da conversação. São Paulo: Editora UNESP, 1995. p.121-60. . As fortunas d' $O$ Cortesão: a recepção européia a 0 cortesão de Castiglione. São Paulo: Editora UNESP, 1997.

BYLEBYL, J . J. Galen on the non-natural causes of variation in the pulse. Bulletin of the History of Medicine, v.45, p.482-5, 1971.

CASTIGLIONE, B. 0 cortesão. São Paulo: Martins Fontes, 1997.

CíCERO. De oratore. Cambridge: Harvard University Press, William Heinemann, 1988. v.1. 
ELIAS, N. O processo civilizador. Rio de J aneiro: Zahar, 1994. v.1: Uma história dos costumes.

ESCOLA DE SALERNO. Regimen sanitatis salernitanum. New York: Augustus M. Kelley, 1970. p.74-5.

FRIEDEM ANN, J . La genèse: au commencement était le rire. Humoresques, v. 1 , p.15-28, 1990.

FRY, W. F. The biology of laughter. Humor, v.7, p.111-26, 1994.

The physiologic effects of humor, mirth, and laughter. J ournal of the American Medical Association, n.267, p.1857-8, 1992.

GARCÍA GÓMEZ, A. M. The Legend of the Laughing Philosopher and its Presence in Spanish Literature (1500-1700). Córdoba: Servicio de Publicaciones de la Universidad de Córdoba, 1984.

HALL, T. S. History of General Physiology, 600 B.C. to 1900. Chicago: The University of Chicago Press, 1975. v.1-2.

HIPÓCRATES. Pseudepigraphic Writings: letters - embassy - speech from the altar - decree, leide. New York: E. J. Brill, 1990. p.55-105.

J OUBERT, L. Traité du ris, contenant son essance, ses causes, et mervelheus effais, curieusesement recerchés, raisonnés $\&$ observés [...]. Paris: Nicolas Cheneav, 1579. Reimpressão fac-similar de Traité du ris, suivi d' un dialogue sur la Cacographie française. Geneva: Slatkine Reprints, 1973.

KOESTLER, A. J ano: uma sinopse. São Paulo: Melhoramentos, 1981.

MACHLINE, V. C. Concepções sobre o riso segundo a fisiologia do riso do século XVI. Revista da Associação Brasileira de Psicoterapia Analítica de Grupo. v.6, p.97-112, 1997.

- Gargântua e Pantagruel: o riso como recurso terapêutico médico-literário no Renascimento. In: GOLDFARB, J . L., FERRAZ, M. H. (Org.) SEM INÁ RIO NACIONAL DE HISTÓRIA DA CIÊNCIA E DA TECNOLOGIA. 5, REUNIÃO DA REDE DE INTERCÂMBIOS PARA A HISTÓRIA E A EPISTEMOLOGIA DAS CIÊNCIAS QUÍM ICAS E BIOLÓGICAS. 3., 1996, São Paulo. A nais... São Paulo: Sociedade Brasileira de História da Ciência, 1998. p.245-55.

. The contribution of Laurent J oubert's Traité du ris to Sixteenth-Century Physiology of Laughter. In: DEBUS, A. G., WALTON, M. T. (Org.). Reading the Book of Nature: the other side of the scientific revolution. Kirksville: Sixteenth Century J ournal Publishers, 1998. p.251-64.

MAGGI, V., LOMBARDI, L. In: . Aristotelis librvm de poetica communes explanationes [...]. Veneza: Officina Erasmiana Vicentij Valgrisij, 1550. Reimpressão fotostática, M unique: Wilhelm Fink, 1969, p.301-17.

OATES, W. J . The doctrine of the mean. The Philosophical Review, v.45, p.382-98, 1936.

OLSON, G. Literature as Recreation in the Later Middle Ages. Ithaca: Cornell University Press, 1986. 
PROVINE, R. R. Laughter. American Scientist, v.84, p.38-45, jan./fev. 1996.

QUINTILIANO. The Institutio oratoria of Quintilian. Cambridge: Harvard University Press, William Heinemann, 1985, v.2, p.439-501.

. The Institutio oratoria of Quintilian. Cambridge: Harvard University Press, William Heinemann, 1985 v.4.

RATHER, L. J. Old and new views of the emotions and bodily changes: wright and Harvey versus Descartes, J ames and Cannon. Clio Medica, v.1, p.1-25, 1965.

ROSEN, G. Uma história da saúde pública. São Paulo: Editora UNESP, Rio de J aneiro: Hucitec, Associação Brasileira de Pós-Graduação em Saúde Coletiva, 1994.

TEM KIN, O. Hippocrates as the physician of Democritus. Gesnerus, v. 42, p.45564, 1985.

VIVES, J. L. The Passions of the Soul: The Third Book of De anima et Vita. Lewinston,Queenston,Lampeter: The Edwin M ellen Press, 1990. 